\title{
Review Article \\ Monitoring, Diagnosis, and Power Forecasting for Photovoltaic Fields: A Review
}

\author{
S. Daliento, ${ }^{1}$ A. Chouder, ${ }^{2}$ P. Guerriero, ${ }^{1}$ A. Massi Pavan, ${ }^{3}$ A. Mellit, ${ }^{4}$ \\ R. Moeini, ${ }^{5}$ and P. Tricoli ${ }^{5}$ \\ ${ }^{1}$ Department of Electrical Engineering and Information Technology (DIETI), University of Naples Federico II, Via Claudio 21, \\ 80125 Naples, Italy \\ ${ }^{2}$ Department of Génie Electrique, Faculty of Technologies, University of M'Sila, BP 166, Ichbelia, M'Sila, Algeria \\ ${ }^{3}$ Department of Engineering and Architecture, University of Trieste, Piazzale Europa 1, 34127 Trieste, Italy \\ ${ }^{4}$ Renewable Energy Laboratory, Faculty of Sciences and Technology, Jijel University, Jijel, Algeria \\ ${ }^{5}$ School of Electronic, Electrical and Systems Engineering, University of Birmingham, Gisbert Kapp Building, Edgbaston, \\ Birmingham B15 2TT, UK
}

Correspondence should be addressed to P. Guerriero; pierluigi.guerriero@unina.it

Received 2 September 2016; Accepted 14 December 2016; Published 11 January 2017

Academic Editor: Wilfried G. J. H. M. Van Sark

Copyright ( $\odot 2017$ S. Daliento et al. This is an open access article distributed under the Creative Commons Attribution License, which permits unrestricted use, distribution, and reproduction in any medium, provided the original work is properly cited.

A wide literature review of recent advance on monitoring, diagnosis, and power forecasting for photovoltaic systems is presented in this paper. Research contributions are classified into the following five macroareas: (i) electrical methods, covering monitoring/diagnosis techniques based on the direct measurement of electrical parameters, carried out, respectively, at array level, single string level, and single panel level with special consideration to data transmission methods; (ii) data analysis based on artificial intelligence; (iii) power forecasting, intended as the ability to evaluate the producible power of solar systems, with emphasis on temporal horizons of specific applications; (iv) thermal analysis, mostly with reference to thermal images captured by means of unmanned aerial vehicles; (v) power converter reliability especially focused on residual lifetime estimation. The literature survey has been limited, with some exceptions, to papers published during the last five years to focus mainly on recent developments.

\section{Introduction}

The photovoltaic (PV) market has witnessed over the last years a remarkable growth as a result of various stimulating factors: the significant cost reduction of the PV modules on the market and the changes on support policies. These factors have made the return on investment of a photovoltaic system more interesting. However, like other industrial processes, a photovoltaic system may be subject during its fabrication to defects and anomalies leading to a reduction of the overall system performance or even to total unavailability. These negative consequences will obviously reduce the productivity of a PV system and therefore its profit. Thus, proper early fault detection and real-time diagnostic are crucial not only for lowering cost and time maintenance, but also to avoid energy loss, damage to equipment, and safety hazards.
Several research papers and institutional body reports, such as IEA, have underlined the low yields of PV systems due to faulty components, especially the DC section (i.e., PV cells/modules and MPPT) [1-9]. Broadly speaking, faults of $\mathrm{PV}$ arrays are categorized as cracks in the cells, delamination, hot spots, dirt accumulation, modules mismatches, short circuit of modules, junction box faults, caused by damaged connections, corrosion of the connections, open circuit, short circuit, and MPPT faults [10]. Obviously, this is not an exhaustive list and many other faults can be found in the literature $[11,12]$.

The basic approach for the detection of unexpected power losses of PV systems uses analytical redundancy, which is a comparison between the monitored electrical quantities (output power, voltage, and current) and their counterparts obtained from a reference model. An alarm is triggered when 
predetermined differences are reached [13-16]. The reference model is often based on the one diode model, whose parameters are determined either by the manufacturer's datasheet or by automatic extraction methods [17]. However, these methods are only effective for the detection and diagnosis of a grouped set of faults but not for an individual location of each defect [18]. Moreover, irradiation and temperature measurements are essential requirements for this approach [15].

Another fault detection and diagnostic method is based on hardware redundancy, in which several similar subsystems undertake the same task. By collecting and analyzing each subsystem's data, abnormalities can be detected. Since monitoring of electrical parameters usually produces a large amount of data, artificial intelligence and data mining are adopted as well. Similar models are adopted for power forecasting, which is important for both monitoring purposes and the management of the utility grid.

Recently, thanks to the widespread diffusion of unmanned aerial vehicles (UAV), thermal analysis is becoming a cost-effective alternative to electrical monitoring. Also the reliability of power converters plays a key role in the correct operations of PV.

The paper is organized as follows: Section 2 describes the monitoring techniques based on the measurement of electrical parameters; Section 3 focuses on the analysis of measured data with artificial intelligence and data mining algorithms; Section 4 is devoted to power forecasting; Section 5 discusses aerial thermal analysis; and Section 6 deals with the reliability of power converters. Conclusions are drawn in Section 7.

\section{Electrical Methods}

This section presents the recent trends for monitoring and diagnosis $(M \& D)$, based on electrical parameters directly acquired from the solar field. In principle, the performance analysis based on such parameters is straightforward, because it is based on the comparison between measurements and predictions. Unfortunately, the large number of unpredictable conditions, which affect the performance of solar panels, poses a serious challenge to the definition of a reliable target for the expected outputs.

The first step towards a suitable monitoring system is the definition of what should be measured, how it can be measured, and how measurements can be handled. The question about what should be measured introduces the first trade-off among possible monitoring/diagnosis approaches, depending on how PV subsystems are grouped. Indeed, the overall performance of a PV system depends on the performance of each subsystem, where the individual subsystem is the single solar cell forming the solar panel. A more pervasive measurement system increases the accuracy of M\&D at the expense of an increased cost. Therefore, a rough classification of M\&D electrical techniques can be based on the "level of granularity" (LoG). The lowest LoG corresponds to the monitoring of the solar field as a whole. In this case, only the instantaneous output power generated by the PV field, at either the DC side or the AC side, is measured and then converted into the energy yield of plant. In this case, the widely adopted figure of merit is the Performance Ratio (PR) defined, according to the IEC 61724 [26], as the ratio between the measured instantaneous power, $P_{i}$, (or the measured cumulated energy) and the nominal power of the solar field, $P_{\text {nom }}$, (or the cumulated energy produced at nominal power rate), corrected by taking into account the actual instantaneous irradiance $G_{i}$. With respect to the irradiance at STC $\left(1 \mathrm{~kW} / \mathrm{m}^{2}\right)$,

$$
\mathrm{PR}=\frac{P_{i}}{P_{\text {nom }}} \frac{G_{\mathrm{STC}}}{G_{i}} .
$$

The main drawback of adopting (1) as figure of merit is that, as well pointed out in [27], the power yield largely depends on the working temperature. In order to take into account thermal effects, an improved version (2) has been proposed:

$$
\operatorname{PR}(T)=\frac{P_{i}}{P_{\text {nom }}+\beta \cdot \Delta T} \frac{G_{\text {STC }}}{G_{i}},
$$

where $\beta$ is the temperature coefficient for the power generated (it is always a negative number) and $\Delta T$ is the temperature increment with respect to $25^{\circ} \mathrm{C}$.

Usually, if PR is lower than 1, the solar system is underperforming. However, the adoption of $P_{\text {nom }}$ in both (1) and (2) does not take into account numerous factors leading to a deviation of the actual performance of the solar field from the nominal target, even though all its components operate correctly. In order to overcome this issue, [27] proposes an improvement of both (1) and (2) by replacing the nominal power with a reference power provided by a detailed model of the solar field. The model works with the same environmental conditions of the real system but with ideal solar panels, thus defining a "relative error" as figure of merit.

The limit of complex models, like those presented in [27], is that their effectiveness is based on the reliability of the model and the capability of extracting from its suitable parameters.

An opposite view is presented in [28], as the model used to predict the PV system electricity production has a low complexity.

For all the cases, the expected ac power $P_{\mathrm{ac}}$, adopted in place of $P_{\text {nom }}$ in (1), is evaluated as

$$
P_{\mathrm{ac}}=G_{i}\left(a_{1}+a_{2} G_{i}+a_{3} \log \left(G_{i}\right)\right)\left(1+a_{4}(\Delta T)\right),
$$

where $a_{1}, a_{2}, a_{3}$, and $a_{4}$ are fitting parameters.

The method proposed in [29] is also very simple. The sophisticated verification (SV) method has the following expression for the PR:

$$
\operatorname{PR}(T)=\frac{P_{i}}{P_{\text {nom }}\left(G_{i} / G_{\mathrm{STC}}\right)}=\frac{P_{\text {nom }}\left(G_{i} / G_{\mathrm{STC}}\right)-L}{P_{\text {nom }}\left(G_{i} / G_{\mathrm{STC}}\right)},
$$

where $L$ is a loss term (explicated in [29]) which includes various effects (temperature, shading mismatches, etc.). The measured energy is then plotted as a function of the irradiance and, according to (4), any deviation from the straight line is attributed to some form of malfunctioning. 
A similar approach is also proposed in [30] with reference to a solar field with thin film panels. In this paper array losses are defined as

$$
L_{\text {Array }}=P_{\text {nom }} \frac{G_{i}}{G_{\mathrm{STC}}}-V_{\mathrm{pv}} \cdot I_{\mathrm{pv}},
$$

where $V_{\mathrm{pv}}$ and $I_{\mathrm{pv}}$ are the measured operating voltage and current of the solar field, respectively.

Once a model for evaluating losses has been selected, another issue common to many papers is data transmission, with the main options being WiFi, GSM, and Power Line Communication (PLC). In [31] it is observed that a drawback of GSM [32] is its high operating cost, as the user needs to pay for the data transmission service; thus, the ZigBee protocol is proposed. In [33] wireless communication is exploited to monitor the effect of dust in solar field installed in the desert. Methods based on the monitoring at the array level have the drawback of not being suitable for locating faulted components. This is a very important issue, because maintenance costs strongly depend on the ability to undertake focused interventions. Therefore, the number of monitored parameters needs to be necessarily increased and move towards a higher LoG. A commonly adopted solution is to use the same figures of merit but refer to a single string rather than the entire system. Actually, the availability of string electrical performance can be also exploited to skip the need for weather information. The comparison among the strings allows the direct identification of the faulty ones. This approach is well illustrated in [34], where currents between strings are compared. In that paper, it was observed that fault detection is difficult when failures occur in multiple strings; the disambiguation is carried out by combining the figures of merit with the evaluation of the standard Performance Ratio.

The definition of a more suitable figure of merit can be found in [35], where an inferential tool, returning information about the operation of the PV field, is presented. After initial training, the software defines one or more reference strings that are used in place of the nominal power for the definition of the expected Performance Ratio. A simple method for defining a reference string was presented in [36, 37]. In those papers the instantaneous power generated by the best performing string in a large solar field is assumed as the target for all other strings with the same orientation. This approach has the advantage of being absolutely independent on weather conditions, irradiance, and temperature and does not require any training of the software. Moreover it allows a fast localization of faulty strings and a reliable estimation of energy losses attributable to each string.

A different approach for analyzing string data is proposed in [38], where a given dataset of observed string currents and voltages and their respective low-pass-filtered time derivatives are analyzed a posteriori for the determination of the probabilities of a restricted set of possible fault that could have caused that dataset.

All the techniques listed so far are based on the comparison of the instantaneous power with a set yield target. An alternative method, which can be found in [39], proposes plotting the whole $I-V$ curve of a single string using information from the inverter. Indeed, the inverter control needs to measure instantaneous voltage and current in order to track the maximum power point. Moreover, as pointed out in [40], some commercial inverters carry out a periodic scan of the entire $I-V$ curve in order to distinguish the global maximum from local ones, in case of mismatch among the modules.

The measurement of the whole $I-V$ curves of single strings, compared with a tailored model, is also proposed in [41] to recognize six categories of faults, including shadow effects, bypass diode fault, cell fault, module fault, and so on.

A possible issue, which is often misrecognized when dealing with string level monitoring techniques, is the possible occurrence of reverse currents in parallel connected string. Paper [42] shows the ineffectiveness of usual rules $(3 \sigma)$ used to recognize underperforming strings, since the current of faulty string always lies between the upper and lower bound of the $3 \sigma$ rule. In order to overcome this problem, a machinelearning local outlier factor (LOF) is defined. This factor provides a quantitative approach to identify the faulty strings (called outliers) by defining a density-based outlier detection rule. This rule is based on the fact that the density around an outlier is significantly different from the density of its neighbors.

An improved fault location capability can be attained by pushing the monitoring at the individual solar panel level. It is obvious that in this case a pervasive sensor network is needed, so that the cost of the system can be justified by higher revenues coming from most effective maintenance strategies. The main issues to be faced when a single panel monitoring system is adopted are the power supply of sensors, data communication, and data management [43], as their effectiveness depends on the monitored parameters. The best performing option [44] consists in measuring the entire $I-V$ curve of each solar panel. This solution is relatively simple to implement in distributed conversion systems [45-49], where each solar panel has its own dc/dc converter that can be properly controlled to plot or estimate the $I-V$ characteristic [50]; other measurements are much more complicated, because they would require the temporary disconnection of individual solar panels from the string.

A more widely adopted solution consists in the measurement of the operating voltage and the operating current of the solar panel to calculate the instantaneous power generated. This approach requires reduced hardware for sensing electrical parameters, while it could be demanding for the power supply, depending on both the adopted communication system and the sampling rate of measurements. For example, [51] proposes GSM, but no details are given about power supply. A possible alternative to GSM is PLC, which exploits the existing dc wiring; in this case it is essential to avoid the fact that signals travel through the solar panels (that are series connected with the dc power cable). To this end, a bypass low impedance path must be provided. Reference [52] proposes connecting a capacitor in parallel with each solar panel, while $[53,54]$ propose a more effective LC filter. PLC is also suggested in [55] to make a fire proof protection system. A heartbeat is sent through the power line to a microcontroller mounted on each solar panel. If the heartbeat is lost, either because the power line is opened on purpose or broken by 
fire, the microcontroller trips a series switch to open the circuit and a parallel switch to short circuit the solar panel.

The main drawback of a single panel monitoring system is that the operating current is the same for all the series connected solar panels and depends on the string operating point, which is fixed by the centralized converter. The consequence is that the operating power cannot be considered as a diagnostic measurement for each individual panel. From this point of view, the most advanced single panel monitoring system is described in [56-59]. In addition to the measurement of operating voltage and current, this system uses both the open circuit voltage, $V_{\text {oc }}$, and shortcircuit current, $I_{\mathrm{sc}}$, which are unique to each solar panel. Moreover, $V_{\mathrm{oc}}$ is an indirect measurement of the temperature while $I_{\mathrm{sc}}$ is directly related to the irradiance, so that no specific sensors are needed for these parameters. In order to carry out the aforementioned measurements, the system physically disconnects the solar panel from the string for about $20 \mathrm{~ms}$, thanks to a series solid state switch. The power of the electronic board is drawn from the solar panel. Since, during the measurement of $I_{\mathrm{sc}}$, the output voltage is zero, a supercapacitor is used as a backup storage to allow the continuous controllability of the circuit. Lastly a cheap WiFi communication system is adopted for data transmission.

A common problem encountered by monitoring systems is the large amount of data to be analyzed. In the next section approaches adopted artificial intelligence and data mining are described.

\section{Artificial Intelligence and Data Mining}

As PV array characteristics are highly nonlinear, the presence of underperformance and faults within the system can lead to uncorrelated effects. Hence, more sophistication and refinement of the algorithms and methods for fault detection and diagnostic are required. One active research area is on the use of artificial intelligence and data mining, which are primarily based on the concept of a knowledge database. These methods can be split into three categories [60-65]: signal processing methods, classification methods, and inference methods. The main idea of signal processing methods is to extract some features of the measured signals, which can be attributed to a particular state of health of the PV system. The most commonly used methods are wavelet transform techniques [66] and Fast Fourier Transform (FFT) [67]. The classification methods are instead based on artificial intelligence, where knowledge is built from an available dataset. As the amount of labeled data is quite large, supervised learning algorithms can learn the characteristics of the system and make the prediction after training. A number of supervised learning models addressing fault detection and diagnostic in PV systems have been proposed in the literature. For instance, artificial neural networks (ANN) have been proposed for PV systems working under partial shading conditions [68]; for the monitoring and supervision of health status of a PV system in [69]; and for short-circuit fault detection of PV arrays in [70]. In other works, Bayesian Neural Network (BNN) and regression polynomial models have been proposed to predict the soiling effects on large-scale PV arrays [71]. Data mining methods for fault detection and isolation in PV systems are also proposed in the literature such as decision-tree method, $K$-nearest neighbor, and support vector machine (SVM).

\section{Forecasting of Power Production in Photovoltaic Plants}

The forecasting of the power generated by a PV plant is a key activity for supporting the monitoring of PV fields [72, 73]. Usually, it makes use of either solar radiation measurements made on module plane or solar radiation data taken from meteorological service providers [74], with the aim being to calculate reference values for energy yield.

Depending on the task required, forecasting techniques can have different timescale: the very short (up to one hour) and short (up to 6 hours) time scales belong to intraday forecasts, while longer forecasts have time scales of one or more days. With reference to the spatial extension, forecasting can be related to a single plant or, for regional models $[75,76]$, a cluster of plants.

As PV systems are greatly influenced by weather conditions, such as solar irradiance and air temperature, accurate models are required for a reliable prediction of their power generation. Many approaches have been developed over the last decades and a good review of them is presented [73, 77]. Models for forecasting the power generated by a PV plant can be broadly classified into three categories. A first type of techniques is based on Numerical Weather Prediction (NPW) for the forecast of meteorological parameters such as the solar irradiance and the air temperature. These parameters are used as the input of a model of the PV system to forecast the power generated. Another approach is based on statistical modelling of the historical record of the power generated. This approach includes regressive (e.g., autoregressive, AR; autoregressive moving average, ARMA; autoregressive integrated moving average, ARIMA, etc.) and Artificial Intelligence (AI) models (e.g., artificial neural networks, ANN; support vector machine, SVM; adaptive neurofuzzy inference system, ANFIS, etc.). Finally, a third way to forecast the power generated by a PV system combines physical and statistical modelling, called hybrid technique [78-80]. Hybrid techniques are usually applied when some of the data required by physical or statistical methods are missing and can also be used for improving the accuracy of the forecasting activity [73]. The three different approaches have different temporal capability: most of the techniques produce short-term predictions, while NPW-based methods are better suited for long-term predictions of up to 15 days [81].

Among the different approaches presented in the literature, where the main challenge is the design of cost-effective models working for different PV technologies, locations, and working conditions, physical, regressive, and ANN-based models are the most applied techniques accounting for $50 \%$ of the reviewed literature [73].

Physical approaches, which represent $11 \%$ of the used techniques [73], use models of the PV system to generate the forecasts, while the major research attempts are spent on solar 
irradiance forecasting [75]. NWP modelling is based on the physical state and on the dynamic motion of atmosphere [75, $77,82-84]$. One of the latest works in this field can be found in [85], where the solar irradiance is forecasted on a dayahead and intraday basis by means of a model provided by the European Center for Medium Range Wheatear Forecasting (ECMWF model). NPW modelling is also used to calculate the temperature that, together with the solar irradiance, usually is the main input of any physical model for the calculation of the power generated [86].

Statistical modelling does not require any information regarding the system to model and use data to predict the future behavior of the plant [73]. These approaches include a number of different types of time series regression models [87], accounting for $14 \%$ of the total forecasting techniques [73]. The mostly used techniques are ARIMA-based models because of their generality [88]. As reported in [89], ARMAX models, which use exogenous inputs, give the best results for this type of modelling.

In a similar way, techniques based on artificial intelligence do not require any information regarding the system and include a number of different approaches: artificial neural networks, fuzzy logic, evolutionary algorithms, expert systems, and others [90]. The most used AI-based techniques use ANN, representing $24 \%$ of the total, and they can be classified as follows.

(i) A first type of ANN-based model estimates the power generated by the PV plant starting from the instantaneous working conditions of solar irradiance and temperature [91-93]. The working conditions can come either from sensors mounted on the field or from NWP-based models.

(ii) Other ANN-based models take as an input the current and the past values of the output power [81, 9496]. These models directly forecast the power output without any additional meteorological parameters.

(iii) A third type of ANN-based models is a combination of the first two types [97-100].

\section{Aerial Thermal Analysis}

As it is widely known, the degradation of long-term performance and overall reliability of PV plants can drastically reduce expected revenues. It should be considered that medium- and large-size plants are composed by thousands of modules, with each one potentially affected by the following main types of faults:

(i) optical degradation or fault: bubbles, delamination, discoloration of the encapsulant, and front cover (i.e., glass) fracture;

(ii) electrical mismatches: cell cracks/fractures, breakage of interconnection ribbons, poor soldering, snail tracks, shunts, shading;

(iii) nonclassified: potential induced degradation (PID), defective/short-circuited bypass diodes, shortcircuited modules or strings, and junction box failure.
Standard monitoring approaches, that is, electrical string monitoring, only ensure power losses detection in a portion of the PV field, while the accurate localization of faulty modules requires strings disassembling, visual inspection, and/or electrical and thermographic analysis. Unfortunately the above-mentioned techniques are time demanding, cause undesired stops of the energy generation, and often require laboratory instrumentation, thus resulting in cost effectiveness only in case of catastrophic faults. Moreover, it should be noted that PV plants are often located in inaccessible places, for example, rooftops, thus making any intervention dangerous. As a consequence, the safety of operation deeply impacts on the maintenance costs.

The introduction of diagnostic techniques provides on one hand rapid detection and effective classification over a large number of faults, but on the other hand they limit monitoring and diagnostics costs. This requires in the majority of PV fields cost-effective O\&M.

In the recent literature $[19-25,37,101-106]$, a new nondestructive diagnostic approach uses unmanned aerial systems (UAS) equipped with thermal and/or visual cameras to inspect PV fields and automatic tools for image processing and fault detection and classification. The main challenges of this approach are
(a) positioning;
(b) individual module identification;
(c) defect detection;
(d) defect classification.

The critical aspect of PV module automatic identification in infrared images (point (b)) has been studied in [107]. Unfortunately, the small 5\% error obtained by means of manual camera increases to $30 \%$ when a drone carries out the measurement from a flying altitude of $20 \mathrm{~m}$.

An automatic defects detection and classification procedure is proposed in [108] for a cell-level analysis. First, the variance and the mean value of the temperature of each pixel of the photograph are calculated for each PV cell. Nonuniform cells, that is, cells exhibiting a large variance in their temperature distribution, are discarded and separately analyzed. Uniform cells are classified into light, medium, and strong hot spot according to their mean temperature. Subsequently, hot cells are classified as a function of the most common defects.

A simple and effective method to identify the frames of PV modules from thermal images is proposed in [109]. This approach relies on the assumption that the solar cells have temperature higher than the metallic frame and there is a sharp transition between the two regions. Moreover, the proposed procedure is capable of classifying the defects by means of the thermal gradient analysis carried out at cell level. The obtained results are promising, but the applicability of aerial inspections is still limited by strict requirements in terms of thermal camera resolution and/or low flight height.

Even though defects in solar panels often cause an increase of the surface temperature, sometimes the poor resolution of the thermal cameras hinders an accurate defect classification. In [20], a double stage procedure is proposed: 
in the first step UAV (in the following also referred to as drone) equipped with a thermal camera provides a preliminary thermal analysis to detect and classify large-size defects, while a subsequent visual inspection with a second drone, equipped by a HD photo camera, provides small-size defects classification. In particular, the first stage detects defective points in the PV field and classifies them depending on their shape and location. The following faults can be identified: (a) interconnection issues, that is, entire module warming; (b) defective bypass diodes, internal short circuits, cell mismatch, and snail trails, that is, isolated hot spots or "patchwork pattern"; (c) partial shadowing and cracks, that is, hot spots and/or polygonal patches. Additional information is obtained by reducing the distance between PV arrays and the UAV, thus allowing a more accurate visual analysis. Indeed, visual images can validate the detection and the classification of defects and failures like browning, bubbles, cracked cell, burning, corrosion, cell or module breakages, white spots, snail tails, discoloration, broken interconnections, solder bond failures, and dirty points.

Nevertheless, some critical aspects have to be addressed for an accurate aerial visual inspection, as reported in [21]:

(i) the vertical photography (axis of the camera perpendicular to the ground) should produce a sort of a map of the PV field, where the objects are slightly affected by perspective issues;

(ii) overlap between two consecutive pictures has to be ensured;

(iii) a given flight height must be respected depending on the specific faults to be detect;

(iv) the stability of the drone has to be ensured by flying without wind (wind speed $<3 \mathrm{~m} / \mathrm{s}$ ) and sunny, cloudless, and clear sky;

(v) there is a need to find suitable flight trajectory to minimize the reflection of objects located near the modules and the sunlight.

In $[22,104]$ images acquired by a light UAV produced an IRT map, that, is thermal orthophotoplan, of the investigated PV installation by means of aerotriangulation methods. In particular, both photogrammetry techniques and global positioning system (GPS) receivers are employed to ensure correct positioning, while an image postprocessing procedure based on Canny edge approach allows highlighting hot spot of photovoltaic modules. Unfortunately no automatic classification tool is suggested, but auxiliary diagnostic measurements (e.g., IRT, $I-V$ characterization, and EL) validate fault detection and qualitatively classify the analyzed results into a specific fault type, corresponding to a specific thermal pattern, $I-V$ characteristic, and EL pattern. Automated diagnostic tools based on aerial thermal analysis are proposed in [23-25, 37].

The system described in $[23,24]$ uses a three-step procedure: (i) undertaking a raw preliminary defects detection; (ii) selecting faulty modules from the thermal image according to health index; (iii) carrying out accurate defects detection and classification. In the first step the thermal image is converted into grayscale and digital filters (namely, rectangular average, rectangular ideal, and Gaussian filters) are applied to the frequency domain. Subsequently, a high-pass filter evidences the hot area in the panel. According to the assumption that a hot area suggests a fault, all the panels showing a high percentage of hot area with respect to the global one are selected for further analyses and their frames are accurately extracted by means of a Laplace filter. In the third step, the Decision Support Center evaluates the defect and failure type and proposes the best solution for the specific plant by comparing actual performance and its monitored history. Nevertheless, there are still no studies tackling the accurate description of the algorithms executed by the Decision Support Center.

An effective statistical data-driven approach is adopted in [25], where the identification of individual modules consists of the following steps: (1) normalization, (2) thresholding, (3) orientation estimation of the photovoltaic modules, and finally (4) correction and refinement. Moreover, in the proposed pipeline, all data corresponding to the detected photovoltaic modules within an infrared image are processed to obtain four sets of features. Suited statistical test highlights outliers, thus suggesting temperature abnormalities caused by module defects. Then, major temperature abnormalities are classified accurately into three main groups: overheated modules, hot spots, and overheated substrings. The method reaches high accuracy level, but the classification is still poor and generic. Table 1 reports information regarding drones and cameras adopted to implement the techniques discussed above.

Results obtained in $[23-25,37]$ suggest that droneassisted diagnostic is going to achieve an important role in O\&M of PV plants thanks to its effectiveness in terms of detection and localization. Moreover, even though these techniques still require high resolution cameras often costly and heavy, as indicated in Table 1, today the market has on offer a growing number of light electric drones with high payload, sophisticated navigation systems mainly based on GPS receivers, and extended flight time. Nevertheless, an accurate classification of defects is still a challenge.

\section{Converter Reliability}

Among possible faults in photovoltaic systems, those associated with $\mathrm{dc} / \mathrm{ac}$ power converters are the most dramatic. In fact, this occurrence completely stops the energy generation. Although a malfunction of the $\mathrm{dc} / \mathrm{ac}$ power converter is easy to detect (even though reference data from inverter manufacturers might be needed), it is not so easy to fix, as it often requires the location and the replacement of damaged devices inside the case. Therefore, the challenge is to prevent failures by estimating the residual lifetime (RLT) of the power modules. RLT algorithms are different in terms of type of applications and module characteristics. In the following, different methods to estimate the expected RLT of IGBT modules based on accelerated life tests are summarized. First, temperature cycling tests are introduced to correlate RLT to temperature stresses. Then, methods for the estimation of the 
TABLE 1: Drones and cameras employed in aerial inspections.

\begin{tabular}{|c|c|c|c|c|c|c|c|c|c|}
\hline \multirow[b]{2}{*}{ Reference } & \multicolumn{2}{|c|}{ Drone } & \multicolumn{5}{|c|}{ Camera } & \multirow[b]{2}{*}{$\begin{array}{c}\text { Thermal } \\
\text { sensitivity }\end{array}$} & \multirow[b]{2}{*}{ Weight } \\
\hline & Model & Propulsion & Type & Pixels & Range & $\begin{array}{l}\text { Temperature } \\
\text { range }\end{array}$ & Accuracy & & \\
\hline & & & GoPRo Hero 3 & $1920 \times 1080$ & - & - & - & - & $76 \mathrm{~g}$ \\
\hline [19] & dji S1000 & Electric & Optris PI 450 + recorder & $382 \times 288$ & $\begin{array}{c}7.5- \\
13 \mu \mathrm{m}\end{array}$ & $\begin{array}{l}-20^{\circ} \mathrm{C} \text { to } 100^{\circ} \mathrm{C} \\
0^{\circ} \mathrm{C} \text { to } 250^{\circ} \mathrm{C} \\
150^{\circ} \mathrm{C} \text { to } 900^{\circ} \mathrm{C}\end{array}$ & $\begin{array}{l} \pm 2^{\circ} \mathrm{C} \text { or } \\
\pm 2 \%\end{array}$ & $0.040 \mathrm{~K}$ & $380 \mathrm{~g}$ \\
\hline & $\begin{array}{l}\text { Nimbus } \\
\text { EosXi }\end{array}$ & Gasoline & $\begin{array}{l}\text { ThermoteknixMicroCAM } \\
640\end{array}$ & $640 \times 480$ & $\begin{array}{c}8- \\
12 \mu \mathrm{m}\end{array}$ & - & - & $0.060 \mathrm{~K}$ & $74 \mathrm{~g}$ \\
\hline$[20]$ & $\begin{array}{l}\text { Nimbus } \\
\text { PLP-610 }\end{array}$ & Electric & Nikon1 V1 HD & $3906 \times 2606$ & - & - & - & - & $383 \mathrm{~g}$ \\
\hline [21] & $\begin{array}{l}\text { Nimbus } \\
\text { PLP-610 }\end{array}$ & Electric & Nikon1 V1 HD & $3906 \times 2606$ & - & - & - & - & $383 \mathrm{~g}$ \\
\hline [22] & $\begin{array}{c}\text { Condor AY } \\
704\end{array}$ & Electric & Optris PI 450 & $382 \times 288$ & $\begin{array}{c}7.5- \\
13 \mu \mathrm{m}\end{array}$ & $\begin{array}{l}-20^{\circ} \mathrm{C} \text { to } 100^{\circ} \mathrm{C} \\
0^{\circ} \mathrm{C} \text { to } 250^{\circ} \mathrm{C} \\
150^{\circ} \mathrm{C} \text { to } 900^{\circ} \mathrm{C}\end{array}$ & $\begin{array}{l} \pm 2^{\circ} \mathrm{C} \text { or } \\
\pm 2 \%\end{array}$ & $0.040 \mathrm{~K}$ & $320 \mathrm{~g}$ \\
\hline $\begin{array}{l}{[23]} \\
{[24]}\end{array}$ & $\begin{array}{l}\text { Nimbus } \\
\text { PLP-610 }\end{array}$ & Electric & Flir A35 & $320 \times 256$ & & $\begin{array}{l}-40^{\circ} \mathrm{C} \text { to } 160^{\circ} \mathrm{C} \\
-40^{\circ} \mathrm{C} \text { to } 550^{\circ} \mathrm{C}\end{array}$ & $\begin{array}{l} \pm 5^{\circ} \mathrm{C} \text { or } \\
\pm 5 \%\end{array}$ & $0.05 \mathrm{~K}$ & $200 \mathrm{~g}$ \\
\hline [25] & $\begin{array}{c}\text { DaVinci } \\
\text { Copters } \\
\text { ScaraBot X8 }\end{array}$ & Electric & GoPRo Hero 3+ & $1920 \times 1080$ & $\begin{array}{c}- \\
7.5- \\
13 \mu \mathrm{m}\end{array}$ & $\begin{array}{c}- \\
-20^{\circ} \mathrm{C} \text { to } 100^{\circ} \mathrm{C} \\
0^{\circ} \mathrm{C} \text { to } 250^{\circ} \mathrm{C} \\
150^{\circ} \mathrm{C} \text { to } 900^{\circ} \mathrm{C}\end{array}$ & $\begin{array}{c}- \\
\pm 2^{\circ} \mathrm{C} \text { or } \\
\pm 2 \%\end{array}$ & $0.04 \mathrm{~K}$ & $76 \mathrm{~g}$ \\
\hline
\end{tabular}

junction temperature (JT) and the temperature humidity bias (THB) tests are presented.

Power modules consist of materials with different thermal expansion coefficients and are subjected to temperature swings due to the variability of the load [110-112]. These stresses lead to a degradation of the module integrity and development of faults, such as heal cracking [113], bond wire lift off (BWLO) [114], and solder fatigue [115]. Corrosion has received recently more attention as IGBT modules are packaged in plastic cases that do not normally offer sufficient moisture resistance.

Due to temperature swings and moisture penetrations, the actual RLT of IGBT modules can be significantly different from the manufacturer's predictions. Thus, these factors should be taken into account to correct online the expected RTL. Condition monitoring systems (CMS) can give an important contribution to this problem, minimizing the risk of failure of IGBTs. CMS gather real-time data on temperature swings and moisture penetration during the operations of converters and use dedicated algorithms to correlate the measurements and update the prediction. These algorithms are based on accelerated life tests, where overstress conditions (high temperature, high temperature cycling, high power cycling, humidity, etc.) are applied to the module to understand in short time the effects of these stresses on the external characteristics and parameters of IGBTs. The CMS will then monitor the stresses in normal conditions and calculate the associated residual lifetime in the correct time scale using the acceleration factor used for the test.
Temperature cycling tests (TCT) refer to the power cycling of IGBT modules at high and low temperatures when the modules are on-state and off-state, respectively. During these tests, both the temperature difference $\Delta T_{j}$ of the junction and the mean value of the junction temperature (JT) need to be collected. The RLT model is obtained from the Palmgren-Miner rule [116]. In this model, the lifetime consumption (LC) is calculated as the ratio of total cycle numbers and number of cycles to failure. The former is obtained from a counting algorithm, like the Rain Flow [117]; the latter is calculated from the Coffin-Manson law [118], which physically models each fault. The RLT is finally estimated by time history (time duration when fault occur) over LC. LCs equal to one or greater than one can be symptoms of being close to failure or occurrence of failure, respectively. The most challenging issue is that TCT rely on JT. Measurement of JT is significantly difficult in a direct way, because of the difficulty in accessing the junction of the module [119]. Different alternative methods have been investigated by researchers to estimate JT, as explained hereinafter.

The JT can be directly measured by temperature sensors [120] and IR cameras [121]. However, due to the slow response of temperature sensors and dependency on the point of installation, the direct method is not recommended. Moreover IR cameras allow only average measurements of relatively large areas of the module and are also not easy to calibrate for the entire range of temperature variations.

The estimation of the JT is preferred to the direct measurement, as it does not require the modification of the 
internal structure of the IGBT [7]. The current estimation methods of JT are based on the measurement and analysis of thermal sensitive electrical parameters (TSEPs). These can be used to obtain the static (e.g., on-state collector-emitter voltage and collector current) and dynamic (e.g., gate parameters and turn-on and turn-off delay times) characteristics of the IGBT under examination. The improvement of models and algorithms for the analysis of indirect measurements of JT is now bringing the indirect methods to the same accuracy levels of their direct counterparts, even when a detection of $\mathrm{JT}$ at fast sampling rate is required.

Kuhn and Mertens [122] and Brown et al. [123] have demonstrated that turn-on and turn-off delay times are positively correlated to JT variations. However, the measurement of these times is challenging for the high sampling rate required to achieve a good accuracy. A second negative aspect of this method is that an increase of the off-state to on-state time $\left(t_{\text {on }}\right)$ and the on-state to off-state time $\left(t_{\text {off }}\right)$ can also be caused by a degradation of the gate-oxide characteristics, which increases the gate-emitter voltage $\left(V_{\mathrm{GE}}\right)$.

Denk and Bakran [124] and Baker et al. [125] showed that the internal gate resistance $\left(R_{\mathrm{Gi}}\right)$ of IGBTs has a negative correlation with JT, so that the value of gate current changes and, hence, the voltage across the external gate resistance linearly increase by a variation of JT. Variation of this voltage has been considered as a TSEP, useful to estimate the JT. The value of the proposed TSEP is accurately measured when the gate voltage is negative; that is, the IGBT is off. However, this method requires an external high frequency sinusoidal voltage signal that has to be superimposed on the negative gate voltage during the off-state time, using auxiliary MOSFET.

Barlini et al. [118] showed that the rates of change of the collector-emitter voltage $\left(V_{\mathrm{CE}}\right)$ and the collector current $\left(I_{\mathrm{C}}\right)$ are linearly related to the JT. However, this relation has been verified only for MOSFETs and it is of difficult practical implementation, because it requires the measurement of time derivatives with high sampling rates.

The measurement of the static $V_{\mathrm{CE}}$ and $I_{\mathrm{C}}$ characteristic of IGBTs has been investigated as another method to estimate the JT [126]. However, this method is not recommended, as the estimated JT is affected by BWLO and the method becomes unreliable if this fault occurs.

As mentioned above, RLT of IGBT modules can be adversely affected by moisture, since the plastic package is not hermetically sealed. Moisture can lead to corrosion of the aluminum inside the module and, hence, faults. Zorn and Kaminski [127] showed that the increase of moisture causes a decrease of avalanche voltage and, above a certain level of humidity, a surge in the leakage current. This leads to temperature stress, especially at the junction the IGBT. Therefore, moisture can significantly decrease RLT of IGBT modules.

The correlation between moisture levels and RLT can be obtained from THB tests. Generally, a THB test is conducted in relative humidity of $85 \%$ and $85^{\circ} \mathrm{C}$ to assess the moisture resistance of the IGBT package. The test voltage applied to the IGBT is used to regulate the leakage current. This voltage should be carefully selected, because if the leakage current heats the module, the moisture evaporates and the degradation effect of humidity becomes less evident [128]. As shown by Zorn and Kaminski [129], the problem is particularly delicate when the test voltage is above the bias voltage (typically $90 \%$ of the nominal voltage), because the leakage current noticeably increases and makes the degradation effect more observable, albeit the higher temperature accelerates the evaporation of moisture.

\section{Conclusions}

This paper has presented a literature survey on reliability issues of photovoltaic fields. The main aspects of the subject have been covered by reviewing papers dealing with data acquisition, data management, and modelling. Tradeoffs among high sensitivity, pervasiveness, hardware requirements, effectiveness, and costs have been pointed out. The abundance of high quality works is an indicator of the relevance of the problem for the scientific community; nevertheless it also evidenced that many issues are still debated and need a more in-depth investigation.

\section{Competing Interests}

The authors declare that they have no competing interests.

\section{Acknowledgments}

Dr. A. Mellit would like to thank the ICTP, Trieste (Italy), for providing the materials and the computers facilities.

\section{References}

[1] S. E. Forman, "Performance of experimental terrestrial photovoltaic modules," IEEE Transactions on Reliability, vol. 31, no. 3, pp. 235-245, 1982.

[2] C. Baltus, J. Eikelboom, and R. Van Zolingen, "Analytical monitoring of losses in pv systems," in Proceedings of the 14th European Photovoltaic Solar Energy Conference, Barcelona, Spain, July 1997.

[3] D. L. King, W. E. Boyson, and J. A. Kratochvil, "Analysis of factors influencing the annual energy production of photovoltaic systems," in Proceedings of the 29th IEEE Photovoltaic Specialists Conference, New Orleans, La, USA, May 2002.

[4] G. Petrone, G. Spagnuolo, R. Teodorescu, M. Veerachary, and M. Vitelli, "Reliability issues in photovoltaic power processing systems," IEEE Transactions on Industrial Electronics, vol. 55, no. 7, pp. 2569-2580, 2008.

[5] A. Chouder and S. Silvestre, "Analysis model of mismatch power losses in pv systems," Journal of Solar Energy Engineering, Transactions of the ASME, vol. 131, no. 2, Article ID 024504, 5 pages, 2009.

[6] M. A. Quintana, D. L. King, T. J. McMahon, and C. R. Osterwald, "Commonly observed degradation in field-aged photovoltaic modules," in Proceedings of the 29th IEEE Photovoltaic Specialists Conference, pp. 1436-1439, May 2002.

[7] P. Guerriero, F. Di Napoli, V. D’Alessandro, and S. Daliento, "Accurate maximum power tracking in photovoltaic systems affected by partial shading," International Journal of Photoenergy, vol. 2015, Article ID 824832, 10 pages, 2015. 
[8] G. Cipriani, V. Di Dio, L. P. Di Noia et al., "A PV plant simulator for testing MPPT techniques," in Proceedings of the 4th International Conference on Clean Electrical Power: Renewable Energy Resources Impact (ICCEP '13), pp. 483-489, Alghero, Italy, June 2013.

[9] G. Brando, A. Dannier, and R. Rizzo, "A sensorless control of Hbridge multilevel converter for maximum power point tracking in grid connected photovoltaic systems," in Proceedings of the International Conference on Clean Electrical Power (ICCEP '07), May 2007.

[10] M. A. Munoz, M. C. Alonso-García, N. Vela, and F. Chenlo, "Early degradation of silicon PV modules and guaranty conditions," Solar Energy, vol. 85, no. 9, pp. 2264-2274, 2011.

[11] S. Daliento and L. Lancellotti, "3D analysis of the performances degradation caused by series resistance in concentrator solar cells," Solar Energy, vol. 84, no. 1, pp. 44-50, 2010.

[12] P. Guerriero, V. D’Alessandro, L. Petrazzuoli, G. Vallone, and S. Daliento, "Effective real-time performance monitoring and diagnostics of individual panels in PV plants," in Proceedings of the 4th International Conference on Clean Electrical Power: Renewable Energy Resources Impact (ICCEP '13), pp. 14-19, Alghero, Italy, June 2013.

[13] D. Stellbogen, "Use of PV circuit simulation for fault detection in PV array fields," in Proceedings of the 23rd IEEE Photovoltaic Specialists Conference, pp. 1302-1307, May 1993.

[14] H. Haeberlin and C. Beutler, "Normalized representation of energy and power for analysis of performance and on-line error detection in PV-systems," in Proceedings of the 13th EU PV Conference on Photovoltaic Solar Energy Conversion, Nice, France, 1995.

[15] A. Drews, A. C. de Keizer, H. G. Beyer et al., "Monitoring and remote failure detection of grid-connected PV systems based on satellite observations," Solar Energy, vol. 81, no. 4, pp. 548-564, 2007.

[16] S. Silvestre, M. A. D. Silva, A. Chouder, D. Guasch, and E. Karatepe, "New procedure for fault detection in grid connected PV systems based on the evaluation of current and voltage indicators," Energy Conversion and Management, vol. 86, pp. 241-249, 2014.

[17] G. T. Klise and J. S. Stein, "Mode used to assess the performance of photovoltaic systems," Tech. Rep., Sandia National Laboratories, 2009.

[18] A. Chouder and S. Silvestre, "Automatic supervision and fault detection of PV systems based on power losses analysis," Energy Conversion and Management, vol. 51, no. 10, pp. 1929-1937, 2010.

[19] U. Muntwyler, E. Schüpbach, and M. Lanz, "Infrared (IR) drone for quick and cheap PV inspection," in Proceedings of the 31st European Photovoltaic Solar Energy Conference and Exhibition, 5CO.15.6, pp. 1804-1806, September 2015.

[20] P. B. Quater, F. Grimaccia, S. Leva, M. Mussetta, and M. Aghaei, "Light Unmanned Aerial Vehicles (UAVs) for cooperative inspection of PV plants," IEEE Journal of Photovoltaics, vol. 4, no. 4, pp. 1107-1113, 2014.

[21] S. Leva, M. Aghaei, and F. Grimaccia, "PV power plant inspection by UAS: correlation between altitude and detection of defects on PV modules," in Proceedings of the 15th IEEE International Conference on Environment and Electrical Engineering (EEEIC '15), pp. 1921-1926, IEEE, Rome, Italy, June 2015.

[22] J. A. Tsanakas, D. Chrysostomou, P. N. Botsaris, and A. Gasteratos, "Fault diagnosis of photovoltaic modules through image processing and Canny edge detection on field thermographic measurements," International Journal of Sustainable Energy, vol. 34, no. 6, pp. 351-372, 2015.

[23] M. Aghaei, F. Grimaccia, C. A. Gonano, and S. Leva, "Innovative automated control system for PV fields inspection and remote control," IEEE Transactions on Industrial Electronics, vol. 62, no. 11, pp. 7287-7296, 2015.

[24] M. Aghaei, A. Gandelli, F. Grimaccia, S. Leva, and R. E. Zich, "IR real-time analyses for PV system monitoring by digital image processing techniques," in Proceedings of the 1st International Conference on Event-Based Control, Communication and Signal Processing (EBCCSP '15), pp. 1-6, Krakow, Poland, June 2015.

[25] S. Dotenco, M. Dalsass, L. Winkler et al., "Automatic detection and analysis of photovoltaic modules in aerial infrared imagery," in Proceedings of the IEEE Winter Conference on Applications of Computer Vision (WACV '16), pp. 1-9, New York, NY, USA, March 2016.

[26] IEC 61724, https://webstore.iec.ch/preview/info_iec61724\% IEC 61724, 7Bed1.0\%7Den.pdf.

[27] F. Bizzarri, A. Brambilla, L. Caretta, and C. Guardiani, "Monitoring performance and efficiency of photovoltaic parks," Renewable Energy, vol. 78, pp. 314-321, 2015.

[28] R. Platon, J. Martel, N. Woodruff, and T. Y. Chau, "Online fault detection in PV systems," IEEE Transactions on Sustainable Energy, vol. 6, no. 4, pp. 1200-1207, 2015.

[29] A. Tahri, T. Oozeki, and A. Draou, "Monitoring and evaluation of photovoltaic system," Energy Procedia, vol. 42, pp. 456-464, 2013.

[30] R. Hariharan, M. Chakkarapani, G. Saravana Ilango, and C. Nagamani, "A method to detect photovoltaic array faults and partial shading in PV systems," IEEE Journal of Photovoltaics, vol. 6, no. 5, pp. 1278-1285, 2016.

[31] F. Shariff, N. A. Rahim, and W. P. Hew, "Zigbee-based data acquisition system for online monitoring of grid-connected photovoltaic system," Expert Systems with Applications, vol. 42, no. 3, pp. 1730-1742, 2015.

[32] M. Gagliarducci, D. A. Lampasi, and L. Podestà, "GSM-based monitoring and control of photovoltaic power generation," Measurement, vol. 40, no. 3, pp. 314-321, 2007.

[33] F. Touati, M. A. Al-Hitmi, N. A. Chowdhury, J. A. Hamad, and A. J. R. San Pedro Gonzales, "Investigation of solar PV performance under Doha weather using a customized measurement and monitoring system," Renewable Energy, vol. 89, pp. 564-577, 2016.

[34] M. Baba, T. Shimakage, and N. Takeuchi, "Examination of fault detection technique in PV systems," in Proceedings of the 35th International Telecommunications Energy Conference 'Smart Power and Efficiency' (INTELEC '13), pp. 431-434, Hamburg, Germany, 2013.

[35] L. Cristaldi, M. Faifer, G. Leone, and S. Vergura, "Reference strings for statistical monitoring of the energy performance of photovoltaic fields," in Proceedings of the 5th International Conference on Clean Electrical Power (ICCEP '15), pp. 591-596, Taormina, Italy, June 2015.

[36] P. Guerriero, G. Vallone, M. Primato et al., "A wireless sensor network for the monitoring of large PV plants," in Proceedings of the 2014 International Symposium on Power Electronics, Electrical Drives, Automation and Motion (SPEEDAM '14), pp. 960-965, Sorrento, Italy, June 2014.

[37] P. Guerriero, F. Di Napoli, and S. Daliento, "Real time monitoring of solar fields with cost/revenue analysis of fault fixing," in Proceedings of the IEEE 16th International Conference on 
Environment and Electrical Engineering (EEEIC '16), Florence, Italy, June 2016.

[38] S. Ben-Menahem and S. C. Yang, "Online photovoltaic array hot-spot Bayesian diagnostics from streaming string-level electric data," in Proceedings of the 38th IEEE Photovoltaic Specialists Conference (PVSC '12), pp. 2432-2437, June 2012.

[39] M. Davarifar, A. Rabhi, A. Hajjaji, E. Kamal, and Z. Daneshifar, "Partial shading fault diagnosis in PV system with discrete wavelet transform (DWT)," in Proceedings of the 3rd International Conference on Renewable Energy Research and Applications (ICRERA '14), pp. 810-814, Milwaukee, Wis, USA, October 2014.

[40] S. Spataru, D. Sera, T. Kerekes, and R. Teodorescu, "Diagnostic method for photovoltaic systems based on light I-V measurements," Solar Energy, vol. 119, pp. 29-44, 2015.

[41] W. Chine, A. Mellit, A. M. Pavan, and V. Lughi, "Fault diagnosis in photovoltaic arrays," in Proceedings of the 5th International Conference on Clean Electrical Power (ICCEP '15), pp. 67-72, Taormina, Italy, June 2015.

[42] Y. Zhao, F. Balboni, T. Arnaud, J. Mosesian, R. Ball, and B. Lehman, "Fault experiments in a commercial-scale PV laboratory and fault detection using local outlier factor," in Proceedings of the 40th IEEE Photovoltaic Specialist Conference (PVSC '14), pp. 3398-3403, Denver, Colo, USA, June 2014.

[43] T. Hu, M. Zheng, J. Tan, L. Zhu, and W. Miao, "Intelligent photovoltaic monitoring based on solar irradiance big data and wireless sensor networks," Ad Hoc Networks, vol. 35, pp. 127136, 2015.

[44] P. Papageorgas, D. Piromalisb, T. Valavanis, S. Kambasis, T. Iliopoulou, and G. Vokas, "A low-cost and fast PV I-V curve tracer based on an open source platform with M2M communication capabilities for preventive monitoring," Energy Procedia, vol. 74, pp. 423-438, 2015.

[45] M. Coppola, P. Guerriero, F. Di Napoli, S. Daliento, D. Lauria, and A. Del Pizzo, "A PV AC-module based on coupledinductors boost DC/AC converter," in Proceedings of the International Symposium on Power Electronics, Electrical Drives, Automation and Motion (SPEEDAM '14), pp. 1015-1020, June 2014.

[46] M. Coppola, P. Guerriero, F. Di Napoli et al., "Modulation technique for grid-tied PV multilevel inverter," in Proceedings of the International Symposium on Power Electronics, Electrical Drives, Automation and Motion (SPEEDAM '16), pp. 923-928, 2016.

[47] P. Guerriero, M. Coppola, F. Di Napoli et al., "Three-phase PV CHB inverter for a distributed power generation system," Applied Sciences, vol. 6, no. 10, article 287, 2016.

[48] M. Coppola, F. D. Napoli, P. Guerriero et al., "Maximum power point tracking algorithm for gridtied photovoltaic cascaded hbridge inverter," Electric Power Components and Systems, vol. 43, no. 8-10, pp. 951-963, 2015.

[49] M. Coppola, S. Daliento, P. Guerriero, D. Lauria, and E. Napoli, "On the design and the control of a coupled-inductors boost dc-ac converter for an individual PV panel," in Proceedings of the 21st International Symposium on Power Electronics, Electrical Drives, Automation and Motion (SPEEDAM '12), pp. 1154-1159, Sorrento, Italy, June 2012.

[50] B. Ando, S. Baglio, A. Pistorio, G. M. Tina, and C. Ventura, "Sentinella: smart monitoring of photovoltaic systems at panel level," IEEE Transactions on Instrumentation and Measurement, vol. 64, no. 8, pp. 2188-2199, 2015.
[51] F. Shariff, N. A. Rahim, and H. W. Ping, "Photovoltaic remote monitoring system based on GSM," in Proceedings of the IEEE Conference on Clean Energy and Technology (CEAT'13), pp. 379383, November 2013.

[52] F. J. Sánchez-Pacheco, P. J. Sotorrío-Ruiz, J. R. Heredia-Larrubia, F. Pérez-Hidalgo, and M. S. De Cardona, "PLC-based PV plants smart monitoring system: field measurements and uncertainty estimation," IEEE Transactions on Instrumentation and Measurement, vol. 63, no. 9, pp. 2215-2222, 2014.

[53] F. Di Napoli, P. Guerriero, V. D’Alessandro, and S. Daliento, "A power line communication on DC bus with photovoltaic strings," in Proceedings of the 3rd Renewable Power Generation Conference (RPG '14), IET, Naples, Italy, September 2014.

[54] J. Han, I. Lee, and K. Sang-Ha, "User friendly Monitoring System for residential PV System Based on Low cost Power Line Communication," IEEE Transactions on Consumer Electronics, vol. 61, no. 2, pp. 175-180, 2015.

[55] F. Di Napoli, P. Guerriero, V. d'Alessandro, and S. Daliento, "Single-panel voltage zeroing system for safe access on PV plants," IEEE Journal of Photovoltaics, vol. 5, no. 5, pp. 14281434, 2015.

[56] P. Guerriero, F. Di Napoli, G. Vallone, V. D’Alessandro, and S. Daliento, "Monitoring and diagnostics of PV plants by a wireless self-powered sensor for individual panels," IEEE Journal of Photovoltaics, vol. 6, no. 1, pp. 286-294, 2015.

[57] V. D’Alessandro, P. Guerriero, S. Daliento, and M. Gargiulo, "Accurately extracting the shunt resistance of photovoltaic cells in installed module strings," in Proceedings of the $3 \mathrm{rd}$ International Conference on Clean Electrical Power: Renewable Energy Resources Impact (ICCEP '11), pp. 164-168, June 2011.

[58] P. Guerriero, V. D’Alessandro, L. Petrazzuoli, G. Vallone, and S. Daliento, "Effective real-time performance monitoring and diagnostics of individual panels in PV plants," in Proceedings of the 4th International Conference on Clean Electrical Power: Renewable Energy Resources Impact (ICCEP '13), pp. 14-19, June 2013.

[59] M. Gargiulo, P. Guerriero, S. Daliento et al., "A novel wireless self-powered microcontroller-based monitoring circuit for photovoltaic panels in grid-connected systems," in Proceedings of the 2010 International Symposium on Power Electronics, Electrical Drives, Automation and Motion (SPEEDAM '10), pp. 164-168, Pisa, Italy, June 2010.

[60] H. Braun, S. T. Buddha, V. Krishnan et al., "Signal processing for fault detection in photovoltaic arrays," in Proceedings of the IEEE International Conference on Acoustics, Speech, and Signal Processing (ICASSP '12), pp. 1681-1684, March 2012.

[61] C. R. Griesbach, "Fault-tolerant solar array control using digital signal processing for peak power tracking," in Proceedings of the 31st Intersociety Energy Conversion Engineering Conference (IECEC '96), pp. 260-265, Washington, DC, USA, August 1996.

[62] H. Braun, S. T. Buddha, V. Krishnan et al., "Signal processing for solar array monitoring, fault detection, and optimization," Synthesis Lectures on Power Electronics, 95 pages, 2012.

[63] Y. Zhao, L. Yang, B. Lehman, J.-F. De Palma, J. Mosesian, and R. Lyons, "Decision tree-based fault detection and classification in solar photovoltaic arrays," in Proceedings of the 27th Annual IEEE Applied Power Electronics Conference and Exposition (APEC '12), pp. 93-99, Orlando, Fla, USA, February 2012.

[64] W. Chine, A. Mellit, V. Lughi, A. Malek, G. Sulligoi, and A. Massi Pavan, "A novel fault diagnosis technique for photovoltaic systems based on artificial neural networks," Renewable Energy, vol. 90, pp. 501-512, 2016. 
[65] A. Al-Amoudi and L. Zhang, "Application of radial basis function networks for solar-array modelling and maximum powerpoint prediction," IEE Proceedings: Generation, Transmission and Distribution, vol. 147, no. 5, pp. 310-316, 2000.

[66] I.-S. Kim, "On-line fault detection algorithm of a photovoltaic system using wavelet transform," Solar Energy, vol. 126, pp. 137145, 2016.

[67] J. A. Momoh and R. Button, "Design and analysis of aerospace DC arcing faults using fast fourier transformation and artificial neural network," in Proceedings of the IEEE Power Engineering Society General Meeting, pp. 788-793, Ontario, Canada, July 2003.

[68] D. D. Nguyen, B. Lehman, and S. Kamarthi, "Performance evaluation of solar photovoltaic arrays including shadow effects using neural network," in Proceedings of the IEEE Energy Conversion Congress and Exposition (ECCE '09), pp. 3357-3362, September 2009.

[69] D. Riley and J. Johnson, "Photovoltaic prognostics and heath management using learning algorithms," in Proceedings of the 38th IEEE Photovoltaic Specialists Conference (PVSC '12), pp. 1535-1539, Austin, Tex, USA, June 2012.

[70] Syafaruddin, E. Karatepe, and T. Hiyama, "Controlling of artificial neural network for fault diagnosis of photovoltaic array," in Proceedings of the 16th International Conference on Intelligent System Applications to Power Systems (ISAP '11), pp. 1-6, IEEE, September 2011.

[71] A. Massi Pavan, A. Mellit, D. De Pieri, and S. A. Kalogirou, "A comparison between BNN and regression polynomial methods for the evaluation of the effect of soiling in large scale photovoltaic plants," Applied Energy, vol. 108, pp. 392-401, 2013.

[72] A. Mellit, A. Massi Pavan, and V. Lughi, "Short-term forecasting of power production in a large-scale photovoltaic plant," Solar Energy, vol. 105, pp. 401-413, 2014.

[73] J. Antonanzas, N. Osorio, R. Escobar, R. Urraca, F. Martinezde-Pison, and F. Antonanzas-Torres, "Review of photovoltaic power forecasting," Solar Energy, vol. 136, pp. 78-111, 2016.

[74] V. d'Alessandro, F. Di Napoli, P. Guerriero, and S. Daliento, "An automated high-granularity tool for a fast evaluation of the yield of PV plants accounting for shading effects," Renewable Energy, vol. 83, pp. 294-304, 2015.

[75] E. Lorenz, T. Scheidsteger, J. Hurka, D. Heinemann, and C. Kurz, "Regional PV power prediction for improved grid integration," Progress in Photovoltaics: Research and Applications, vol. 19, no. 7, pp. 757-771, 2011.

[76] J. G. Da Silva Fonseca, T. Oozeki, H. Ohtake, T. Takashima, and K. Ogimoto, "Regional forecasts of photovoltaic power generation according to different data availability scenarios: a study of four methods," Progress in Photovoltaics: Research and Applications, vol. 23, no. 10, pp. 1203-1218, 2015.

[77] M. Q. Raza, M. Nadarajah, and C. Ekanayake, "On recent advances in PV output power forecast," Solar Energy, vol. 136, pp. 125-144, 2016.

[78] M. Bouzerdoum, A. Mellit, and A. M. Pavan, "A hybrid model (SARIMA-SVM) for short-term power forecasting of a smallscale grid-connected photovoltaic plant," Solar Energy, vol. 98, pp. 226-235, 2013.

[79] P. Ramsami and V. Oree, "A hybrid method for forecasting the energy output of photovoltaic systems," Energy Conversion and Management, vol. 95, pp. 406-413, 2015.

[80] D. P. Larson, L. Nonnenmacher, and C. F. M. Coimbra, "Dayahead forecasting of solar power output from photovoltaic plants in the American Southwest," Renewable Energy, vol. 91, pp. 11-20, 2016.

[81] M. Ding, L. Wang, and R. Bi, "An ANN-based approach for forecasting the power output of photovoltaic system," Procedia Environmental Sciences C, vol. 11, pp. 1308-1315, 2011.

[82] S. Pelland, J. Remund, J. Kleissl, T. Oozeki, and K. De Brabandere, "Photovoltaic and solar forecasting: state of the art," IEA PVPS Task, vol. 14, pp. 1-36, 2013.

[83] S. Pelland, G. Galanis, and G. Kallos, "Solar and photovoltaic forecasting through post-processing of the Global Environmental Multiscale numerical weather prediction model," Progress in Photovoltaics: Research and Applications, vol. 21, no. 3, pp. 284296, 2013.

[84] J. Zhang, B.-M. Hodge, J. Simmons et al., "Baseline and target values for PV forecasts: toward improved solar power forecasting," in Proceedings of the IEEE Power and Energy Society General Meeting (PESGM '15), Denver, Colo, USA, July 2015.

[85] P. Lauret, E. Lorenz, and M. David, "Solar forecasting in a challenging insular context," Atmosphere, vol. 7, no. 2, p. 18, 2016.

[86] E. Lorenz, J. Kühnert, B. Wolff, A. Hammer, O. Kramer, and D. Heinemann, "PV power predictions on different spatial and temporal scales integrating PV measurements, satellite data and numerical weather predictions," in Proceedings of the 29th European Photovoltaic Solar Energy Conference and Exhibition (EUPVSEC '14), pp. 22-26, Amsterdam, The Netherlands, September 2014.

[87] P. Alan, Forecasting with Dynamic Regression Models, John Wiley \& Sons, 1991.

[88] G. E. Box, G. M. Jenkins, G. C. Reinsel, and G. M. Ljung, Time Series Analysis: Forecasting and Control, John Wiley \& Sons, New York, NY, USA, 2015.

[89] Y. Li, Y. Su, and L. Shu, "An ARMAX model for forecasting the power output of a grid connected photovoltaic system," Renewable Energy, vol. 66, pp. 78-89, 2014.

[90] A. Mellit and S. A. Kalogirou, "Artificial intelligence techniques for photovoltaic applications: a review," Progress in Energy and Combustion Science, vol. 34, no. 5, pp. 574-632, 2008.

[91] L. A. Fernandez-Jimenez, A. Muñoz-Jimenez, A. Falces et al., "Short-term power forecasting system for photovoltaic plants," Renewable Energy, vol. 44, pp. 311-317, 2012.

[92] A. Mellit and A. M. Pavan, "A 24-h forecast of solar irradiance using artificial neural network: application for performance prediction of a grid-connected PV plant at Trieste, Italy," Solar Energy, vol. 84, no. 5, pp. 807-821, 2010.

[93] F. Almonacid, C. Rus, L. Hontoria, and F. J. Muñoz, "Characterisation of PV CIS module by artificial neural networks. A comparative study with other methods," Renewable Energy, vol. 35, no. 5, pp. 973-980, 2010.

[94] E. Izgi, A. Öztopal, B. Yerli, M. K. Kaymak, and A. D. Şahin, "Short-mid-term solar power prediction by using artificial neural networks," Solar Energy, vol. 86, no. 2, pp. 725-733, 2012.

[95] P. Mandal, S. T. S. Madhira, J. Meng, and R. L. Pineda, "Forecasting power output of solar photovoltaic system using wavelet transform and artificial intelligence techniques," Procedia Computer Science, vol. 12, pp. 332-337, 2012.

[96] A. Mellit and S. Shaari, "Recurrent neural network-based forecasting of the daily electricity generation of a Photovoltaic power system," in Proceedings of the Ecological Vehicle and Renewable Energy (EVER '09), pp. 26-29, Monte-Carlo, Monaco, March 2009. 
[97] T. T. Teo, T. Logenthiran, and W. L. Woo, "Forecasting of photovoltaic power using extreme learning machine," in Proceedings of the IEEE Innovative Smart Grid Technologies-Asia (ISGT ASIA '15), November 2015.

[98] C. Chen, S. Duan, T. Cai, and B. Liu, "Online 24-h solar power forecasting based on weather type classification using artificial neural network," Solar Energy, vol. 85, no. 11, pp. 2856-2870, 2011.

[99] S. Daliento, L. Mele, E. Bobeico, L. Lancellotti, and P. Morvillo, "Analytical modelling and minority current measurements for the determination of the emitter surface recombination velocity in silicon solar cells," Solar Energy Materials and Solar Cells, vol. 91, no. 8, pp. 707-713, 2007.

[100] S. Daliento and L. Mele, "Approximate closed-form analytical solution for minority carrier transport in opaque heavily doped regions under illuminated conditions," IEEE Transactions on Electron Devices, vol. 53, no. 11, pp. 2837-2839, 2006.

[101] H. Denio III, "Aerial solar Thermography and condition monitoring of photovoltaic systems," in Proceedings of the 38th IEEE Photovoltaic Specialists Conference (PVSC '12), pp. 613-618, Austin, Tex, USA, June 2012.

[102] P. Guerriero, F. Di Napoli, M. Coppola, and S. Daliento, "A new bypass circuit for hot spot mitigation," in Proceedings of the International Symposium on Power Electronics, Electrical Drives, Automation and Motion (SPEEDAM '16), pp. 1067-1072, June 2016.

[103] N. Tyutyundzhiev, F. Martinez-Moreno, J. Leloux, and L. Narvarte, "Equipment and procedures for on-site testing of PV plants and BIPV," in Proceedings of the 29th European Photovoltaic Solar Energy Conference and Exhibition (PVSEC '14), pp. 3499-3503, 2014.

[104] J. A. Tsanakas, G. Vannier, A. Plissonnier, D. L. Ha, and F. Barruel, "Fault diagnosis and classification of large-scale photovoltaic plants through aerial orthophoto thermal mapping," in Proceedings of the 31st European Photovoltaic Solar Energy Conference and Exhibition 2015, pp. 1783-1788, Hamburg, Germany, August 2016.

[105] J. R. Martinez-De Dios and A. Ollero, "Automatic detection of windows thermal heat losses in buildings using UAVS," in Proceedings of the World Automation Congress (WAC '06), Budapest, Hungary, June 2006.

[106] F. Grimaccia, M. Aghaei, M. Mussetta, S. Leva, and P. B. Quater, "Planning for PV plant performance monitoring by means of unmanned aerial systems (UAS)," International Journal of Energy and Environmental Engineering, vol. 6, no. 1, pp. 47-54, 2015.

[107] G. Leotta, P. M. Pugliatti, A. D. Stefano, F. Aleo, and F. Bizzarri, "Post processing technique for thermo-graphic images provided by drone inspections," in Proceedings of the 31st European Photovoltaic Solar Energy Conference and Exhibition (EU PVSEC '15), pp. 1799-1803, Hamburg, Germany, 2015.

[108] S. Vergura, F. Marino, and M. Carpentieri, "Processing infrared image of PV modules for defects classification," in Proceedings of the International Conference on Renewable Energy Research and Applications (ICRERA '15), pp. 1337-1341, IEEE, Palermo, Italy, November 2015.

[109] P. Guerriero, G. Cuozzo, and S. Daliento, "Health diagnostics of PV panels by means of single cell analysis of thermographic images," in Proceedings of the IEEE 16th International Conference on Environment and Electrical Engineering (EEEIC '16), Florence, Italy, June 2016.
[110] N. I. Tziavos, H. Hemida, N. Metje, and C. Baniotopoulos, "Grouted connections on offshore wind turbines: a review," Proceedings of the Institution of Civil Engineers-Engineering and Computational Mechanics, vol. 169, no. 4, pp. 183-195, 2016.

[111] L. Piegari and R. Rizzo, "A control technique for doubly fed induction generators to solve flicker problems in wind power generation," in Proceedings of the 1st International Power and Energy Conference (PECon '06), pp. 19-23, November 2006.

[112] G. Brando, A. Danmer, A. Del Pizzo, and R. Rizzo, "A generalized modulation technique for multilevel converters," in Proceedings of the International Conference on Power Engineering, Energy and Electrical Drives (POWERENG '07), April 2007.

[113] B. Ji, V. Pickert, B. Zahawi, and M. Zhang, "In-situ bond wire health monitoring circuit for IGBT power modules," in Proceedings of the 6th IET International Conference on Power Electronics, Machines and Drives (PEMD '12), pp. 1-6, March 2012.

[114] V. N. Popok, K. B. Pedersen, P. K. Kristensen, and K. Pedersen, "Comprehensive physical analysis of bond wire interfaces in power modules," Microelectronics Reliability, vol. 58, pp. 58-64, 2016.

[115] A. Morozumi, K. Yamada, T. Miyasaka, S. Sumi, and Y. Seki, "Reliability of power cycling for IGBT power semiconductor modules," IEEE Transactions on Industry Applications, vol. 39, no. 3, pp. 665-671, 2003.

[116] R. Bayerer, T. Herrmann, T. Licht, J. Lutz, and M. Feller, "Model for power cycling lifetime of IGBT modules-various factors influencing lifetime," in Proceedings of the 5th International Conference on Integrated Power Systems (CIPS '08), pp. 1-6, VDE, Nuremberg, Germany, March 2008.

[117] M. Denk and M.-M. Bakran, "Comparison of counting algorithms and empiric lifetime models to analyze the load-profile of an IGBT power module in a hybrid car," in Proceedings of the 3rd International Electric Drives Production Conference (EDPC '13), pp. 1-6, IEEE, October 2013.

[118] D. Barlini, M. Ciappa, M. Mermet-Guyennet, and W. Fichtner, "Measurement of the transient junction temperature in MOSFET devices under operating conditions," Microelectronics Reliability, vol. 47, no. 9-11, pp. 1707-1712, 2007.

[119] R. Moeini, P. Tricoli, and H. Hemida, "Increasing the reliability of wind turbines using condition monitoring of semiconductor devices: a review," in Renewable Power Generation, IET, 2016.

[120] R. Schmidt and U. Scheuermann, "Using the chip as a temperature sensor-the influence of steep lateral temperature gradients on the Vce(T)-measurement," in Proceedings of the 13th European Conference on Power Electronics and Applications (EPE '09), pp. 5-11, Barcelona, Spain, September 2009.

[121] W. Brekel, T. Duetemeyer, G. Puk, and O. Schilling, "Time resolved in situ Tvj measurements of $6.5 \mathrm{kV}$ IGBTs during inverter operation," in Proceedings of the PCIM Europe Conference, pp. 808-813, Nuremberg, Germany, May 2009.

[122] H. Kuhn and A. Mertens, "On-line junction temperature measurement of IGBTs based on temperature sensitive electrical parameters," in Proceedings of the 13th European Conference on Power Electronics and Applications (EPE '09), 10, 1 pages, September 2009.

[123] D. W. Brown, M. Abbas, A. Ginart, I. N. Ali, P. W. Kalgren, and G. J. Vachtsevanos, "Turn-off time as an early indicator of insulated gate bipolar transistor latch-up," IEEE Transactions on Power Electronics, vol. 27, no. 2, pp. 479-489, 2012.

[124] M. Denk and M.-M. Bakran, "An IGBT driver concept with integrated real-time junction temperature measurement," in 
Proceedings of the International Exhibition and Conference for Power Electronics, Intelligent Motion, Renewable Energy and Energy Management (PCIM '14), pp. 214-221, May 2014.

[125] N. Baker, S. Munk-Nielsen, M. Liserre, and F. Iannuzzo, "Online junction temperature measurement via internal gate resistance during turn-on," in Proceedings of the IEEE 16th European Conference on Power Electronics and Applications (EPE '14ECCE Europe), pp. 1-10, August 2014.

[126] S. Bęczkowski, P. Ghimre, A. R. Vega, S. Munk-Nielsen, and P. Th, "Online Vce measurement method for wear-out monitoring of high power IGBT modules," in Proceedings of the 15th European Conference on Power Electronics and Applications (EPE '13), pp. 1-7, IEEE, Lille, France, 2013.

[127] C. Zorn and N. Kaminski, "Acceleration of temperature humidity bias (THB) testing on IGBT modules by high bias levels," in Proceedings of the 27th IEEE International Symposium on Power Semiconductor Devices and IC's (ISPSD '15), pp. 385-388, May 2015.

[128] N. Flourentzou, V. G. Agelidis, and G. D. Demetriades, "VSCbased HVDC power transmission systems: an overview," IEEE Transactions on Power Electronics, vol. 24, no. 3, pp. 592-602, 2009.

[129] C. Zorn and N. Kaminski, "Temperature humidity bias (THB) testing on IGBT modules at high bias levels," in Proceedings of the 8th International Conference on Integrated Power Systems (CIPS '14), pp. 1-7, 2014. 

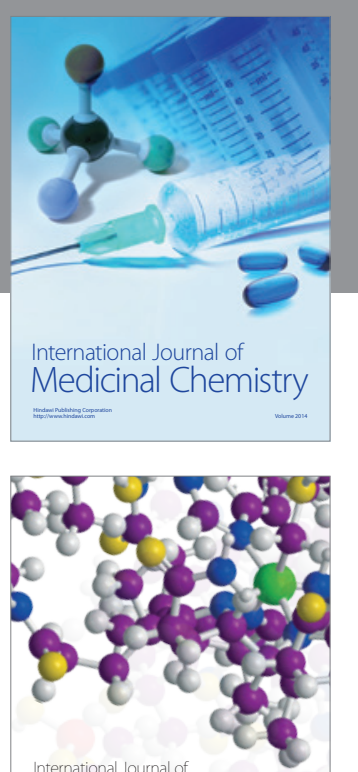

Carbohydrate Chemistry

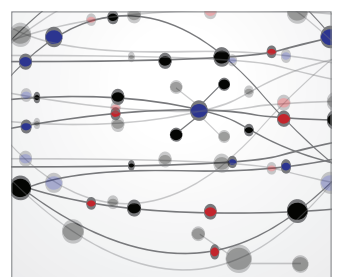

The Scientific World Journal
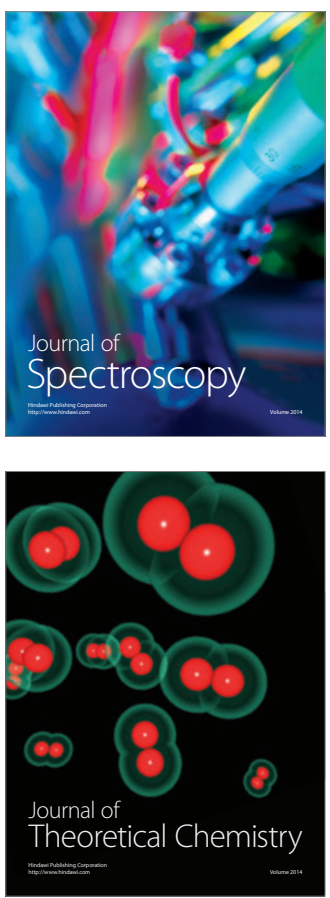
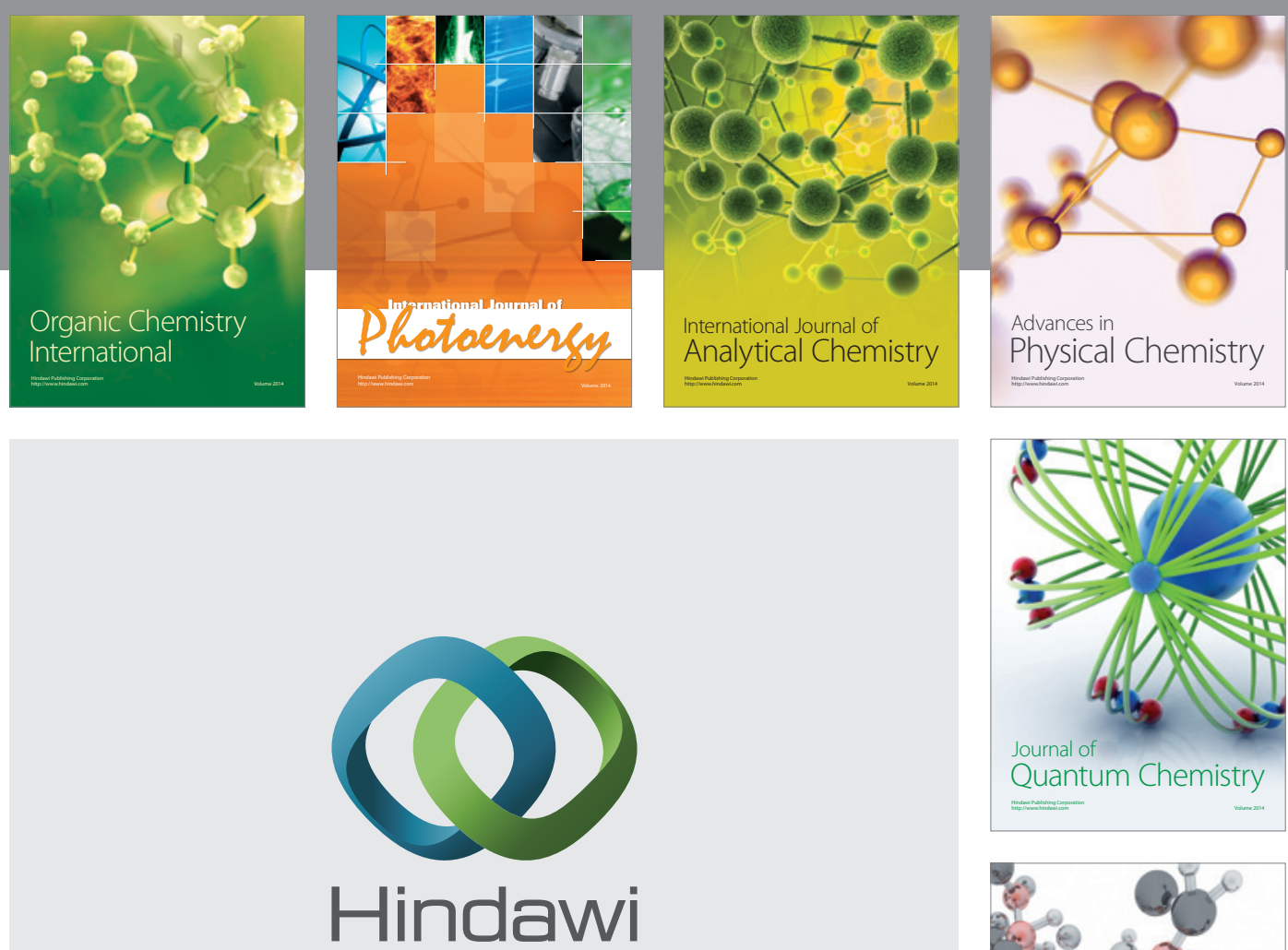

Submit your manuscripts at

https://www.hindawi.com

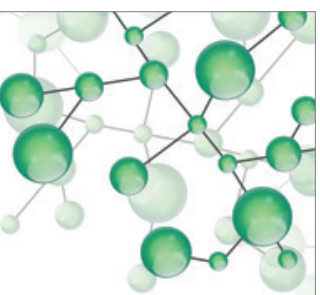

International Journal of

Inorganic Chemistry
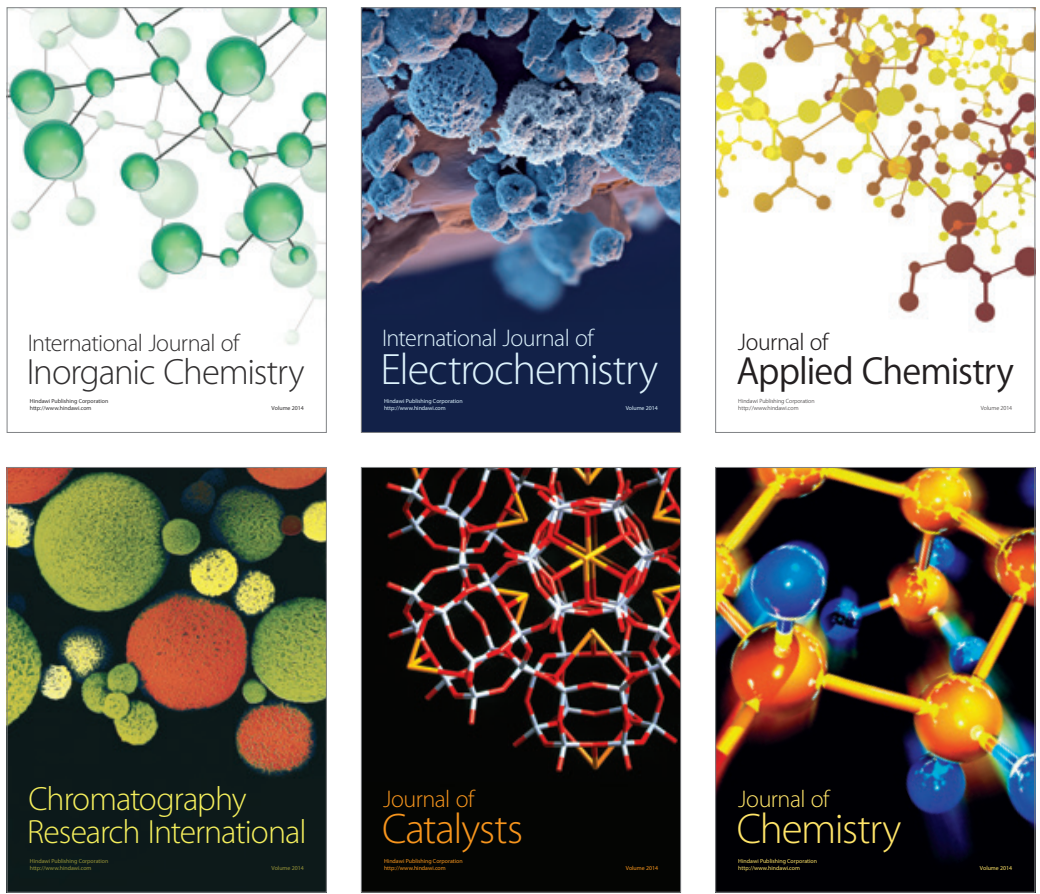

Journal of

Applied Chemistry
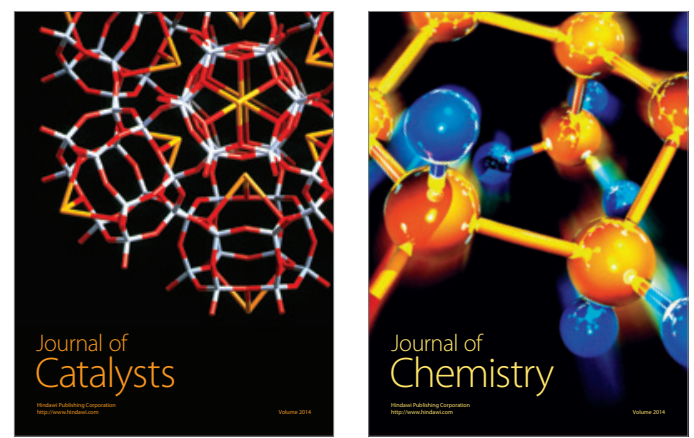
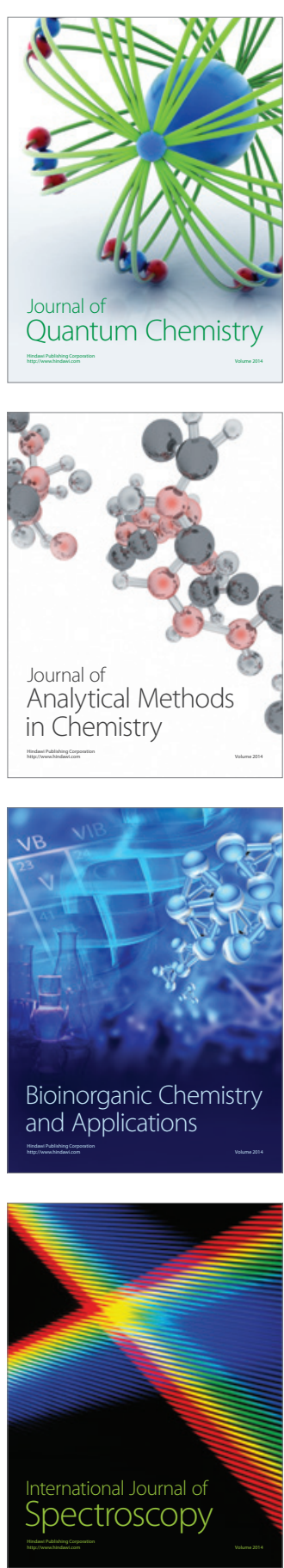